\title{
Acute hookworm infection revealed by capsule endoscopy
}

A 39-year-old man presented at hospital having suffered from watery diarrhea for 10 days. He had also had fever, chills and periumbilical cramping pain for 3 days. He had recently traveled to Jakarta and had taken snake's blood and gall 2 days before diarrhea developed. Blood tests showed leukocytosis $(13070 / \mu \mathrm{l})$, eosinophilia $(6414$ cells $/ \mu \mathrm{l})$ and an increased serum IgE level (360 IU/ml). His hemoglobin count was $17.2 \mathrm{~g} / \mathrm{dl}$, and a fecal smear demonstrated some ova. Colonoscopy revealed two parasites, both about $1 \mathrm{~cm}$ long, with one in the ascending colon (Figure 1) and the other in the sigmoid colon. They were extracted endoscopically and proved to be hookworms (Ancylostoma species). A capsule endoscopy was arranged in order to define the extent of the parasitic infection and rule out the possibility of other small-intestinal diseases (Video). The capsule endoscopy examination identified several worms in the stomach, duodenum, jejunum and proximal ileum. Figure 2 shows a hookworm in the jejunum, which was sucking blood, with the worm's body turning red. The patient's symptoms subsided after a 3-day course of mebendazole treatment.

\section{Competing interests: None}

Endoscopy_UCTN_Code_CCL_1AC_2AG

Endoscopy_UCTN_Code_CCL_1AD_2AJ

\section{Video}

online content including video sequences viewable at:

www.thieme-connect.de/ejournals/abstract/ endoscopy/doi/10.1055/s-2006-944698

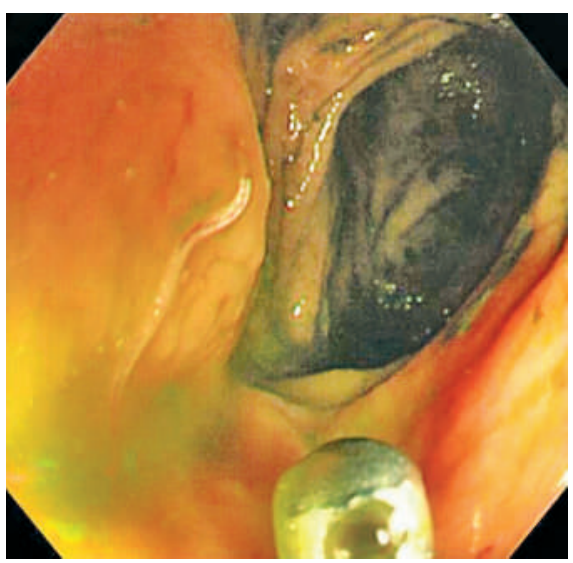

Corresponding Author

\section{C. Wu, M.D., Ph.D.}

Division of Gastroenterology

Kaohsiung Medical University Hospital 100 Zih-You 1st Road

Kaohsiung City 807

Taiwan

Fax: $\quad$ +886-7-3135612

E-mail: dechwu@yahoo.com
Figure 1 A worm was seen on the colonic wall and was extracted by colonoscopy.

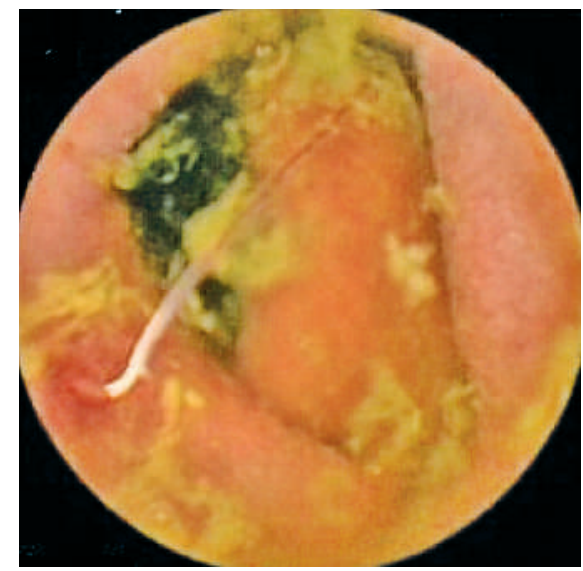

Figure 2 Capsule endoscopy revealed a worm in the jejunum.

\section{C. Wu, C. Y. Lu, D. C. Wu}

Division of Gastroenterology, Dept. of Internal Medicine, Kaohsiung Medical University Hospital, Kaohsiung, Taiwan. 